\title{
Capacitação tecnológica e inovação nas empresas brasileiras: balanço e perspectivas
}

\author{
Anne- Marie Maculan*
}

\section{Resumo}

0 artigo tem por objetivo analisar o processo de capacitação tecnológica da indústria brasileira utilizando as informações publicadas pelo IBGE no relatório PINTEC 2000. Procura-se identificar a natureza e a intensidade das atividades inovadoras, o grau de novidade das mudanças implementadas, as fontes de informação utilizadas e a interação com fornecedores ou compradores. As relações de cooperação com outras empresas ou instituições de pesquisa permitem relacionar as práticas e o desempenho inovador com a possível existência de um sistema nacional de inovação e com os desafios do processo inovador no contexto da economia baseada no conhecimento. Em conclusão as empresas inovam sim mas de maneira tradicional com a modernização tecnológica mais de como introdução de novos produtos e mais pela substituição de máquinas mais de com a partir de investimentos em P\&D.

Palavras-chave: inovação, indústria brasileira e capacitação tecnológica.

\begin{abstract}
In this paper we examine the process of technological capability building in the Brazilian industry. The paper is based on the IBGE PINTEC report published in 2002. A discussion is made about the nature and the intensity of the firm's innovative activities, the novelty of the implemented changes, the sources of information, and the interrelations with suppliers and customers. We investigate the cooperation relations between firms and research institutions, looking for the existence of a national system of innovation. We investigate the impact of this relationship on the innovative performance of the firms in the context of the knowledge-based economy. Finally, we argue that the innovations introduced by the Brazilian industrial firms are closer to a casual process of equipment modernization rather than to the development of new products or processes based on $R \& D$ investments.
\end{abstract}

Key-words: Innovation, Brazilian industry and technological capability

\section{Introdução: Uma nova problemática para a inovação?}

Hoje em dia, existe consenso quanto ao fato que o crescimento e a competitividade de uma economia dependem fortemente de sua capacidade de gerar e empregar novos conhecimentos. Em 1996, um estudo da Organização para Cooperação e Desenvolvimento Econômico (OECD, 1996) ${ }^{1}$ considerava que mais de $50 \%$ do Produto Interno Bruto (PIB) das economias mais avançadas decorria diretamente da produção e aplicação de novos conhecimentos. Mas o acesso ao conhecimento não é um caminho livre de obstáculos e de dificuldades, e a capacidade de inovar não é distribuída de maneira igualitária, nem entre empresas nem entre economias. Ela resulta de um processo gradual de capacitação, ao mesmo tempo, coletivo para uma economia e específico para um setor ou uma empresa.

Em um sistema econômico fortemente internacionalizado e competitivo, as empresas são levadas a melhorar permanentemente sua capacidade de inovação. Essa é uma estratégia inevitável para racionalizar custos, ganhar

\footnotetext{
* Professora e coordenadora do Programa de Engenharia de Produção da Coordenação dos Programas de Pós- graduação de Engenharia (COPPE), Universidade Federal do Rio de Janeiro (UFRJ). E-mail: amaculan@ pep.ufrj.br. Endereço: Programa de Engenharia de Produção, CP 68507 COPPE/UFRJ/CT. CEP: 21941-972 Rio de JaneiroRJ Artigo aceito para publicação em novembro de 2004 e aceito em março de 2005.
}

1 Organization for Economic Cooperation and Development (OECD): www.oecd.org 
maior eficiência no processo produtivo, oferecer produtos novos - com melhor desempenho ou maior funcionalidade -, mantendo-se à frente dos concorrentes e ampliando a atuação no mercado. Portanto, a capacitação tecnológica é o caminho para se conseguir responder às pressões competitivas.

As empresas brasileiras são tradicionalmente consideradas pouco propensas a inovar, freqüentemente tendo dificuldades na gestão tecnológica. Nos anos 1970, as políticas de industrialização centradas na substituição de importações estimularam a transferência de tecnologia de origem externa. A compra de máquinas e os contratos de know-how foram as principais formas de difundir o progresso técnico e incrementar a capacidade produtiva da indústria. Entretanto, implementar capacidade de produção não resulta automaticamente em capacitação tecnológica. Esta se refere a um processo de aprendizado lento e complexo, historicamente condicionado por características socioeconômicas e culturais. Para inovar, é necessário adquirir competências específicas, buscar e articular entre si conhecimentos de natureza e origem diversas; alguns públicos e explícitos, outros, tácitos, vindo da experiência, cuja transmissão, assimilação e utilização são bastante complexas.

Em um nível empírico, há uma extrema carência de informações e estudos sobre a capacitação tecnológica e as práticas inovadoras das empresas brasileiras. Essa carência está sendo, aos poucos, minorada por análises setoriais ou regionais, ou estudos de caso, que permitem entender melhor o comportamento das empresas.

Em 2000, o Instituto Brasileiro de Geografia e Estatística (IBGE) realizou uma ampla pesquisa sobre inovação na indústria brasileira. Considerando que o processo tecnológico é crucial para o desenvolvimento econômico, o IBGE julgou necessário reunir informações que permitissem entender o processo de geração, difusão e incorporação das inovações pelo sistema produtivo brasileiro, fundamentais para a implantação de políticas que promovam a inovação (IBGE, 2002). Os resultados publicados apresentam um quadro detalhado da natureza das atividades que visam à inovação das estratégias e das modalidades de gestão da tecnologia das empresas industriais.

O objetivo deste artigo é interpretar essas informações à luz das abordagens teóricas sobre o processo de inovação, analisar as iniciativas que visam à inovação por parte das empresas, bem como refletir sobre o processo de capacitação tecnológica da indústria brasileira. Pretende verificar se as empresas continuam com estratégias tecnológicas baseadas na aquisição de pacotes tecnológicos, como nos anos 1970, ou se procuram acompanhar a evolução das economias mais avançadas, reconhecendo a importância de gerar conhecimento e investir internamente em pesquisa.

\section{As características do processo de capacitação para a inovação}

O estudo do IBGE utiliza a definição do que seja inovação que consta no Manual de Oslo ${ }^{2}$ e segue a lógica do questionário elaborado pela Eurostat, a agência oficial de estatísticas da Comissão Européia, para o Third Community Innovation Survey. ${ }^{3}$ Por inovação tecnológica, entende-se a colocação no mercado de um produto (bem ou serviço) tecnologicamente novo ou substancialmente aprimorado ou, mesmo, a adoção pela empresa de um processo produtivo tecnologicamente novo ou significativamente aprimorado.

A pesquisa do IBGE apresenta os resultados por setores de atividades ${ }^{4}$ e por tamanho da empresa, identificando a natureza e a intensidade das atividades inovadoras, o grau de novidade das mudanças implementadas, as fontes de informação utilizadas e a interação com fornecedores ou compradores. As informações sobre o comportamento das organizações e as relações de cooperação com outras empresas ou instituições de pesquisa ou treinamento permitem relacionar as práticas e o desempenho inovador daquelas com a possível existência de

\footnotetext{
${ }^{2}$ A primeira versão foi publicada pela OECD em 1992 e revisada em 1997.

${ }^{3}$ European Comission (2004) <http://epp.eurostat.cec.eu.int>

${ }^{4}$ As empresas pesquisadas pertencem a mais de 30 setores diferentes de atividades de transformação.
} 
um sistema nacional de inovação. O estudo traz elementos importantes para entender as estratégias utilizadas pelas empresas para desenvolver inovações e implantar mudanças tecnológicas.

O questionário utilizado na pesquisa incorpora os principais conceitos da economia da inovação, na sua vertente evolucionista. A inovação se refere a produto e/ou processo novo (ou substancialmente aprimorado) para a empresa, não sendo, necessariamente, novo para o mercado/setor de atuação, podendo ter sido desenvolvido pela empresa ou por outra empresa/instituição. Pode resultar de novos desenvolvimentos tecnológicos, de novas combinações de tecnologias existentes ou da utilização de outros conhecimentos adquiridos. Em seguida, lembraremos alguns desses conceitos que possibilitam interpretar os resultados apresentados pela Pesquisa Industrial Inovação Tecnológica (Pintec) 2000.

\subsection{Inovação e busca de conhecimento}

Para inovar, as empresas precisam reunir e combinar informações e conhecimentos gerados, em parte, internamente, nas suas diversas unidades e, em parte, externamente, em outras empresas ou instituições. Os conhecimentos de origem interna são produtos de uma dupla dinâmica. Por um lado, as empresas podem desenvolver atividades de pesquisa para gerar novos produtos ou novas soluções. A existência dessas estruturas internas de pesquisa e desenvolvimento não é muito comum. São mais freqüientes nas grandes empresas e em alguns setores como a indústria farmacêutica, a indústria eletrônica ou o setor de instrumentação. Por outro lado, as experiências ligadas à organização das atividades produtivas representam uma importante fonte de conhecimentos que permitem resolver problemas práticos ou atender melhor às demandas dos usuários ou compradores. Esses conhecimentos gerados a partir das experiências, são freqüientemente tácitos, incorporados formalmente nos procedimentos operacionais, ou informalmente, nas rotinas das empresas. A possibilidade de memorizar e utilizar esses conhecimentos é condicionada tanto pela capacidade cognitiva dos indivíduos quanto pela estrutura organizacional das empresas; e diversas ações gerenciais podem ampliar a capacidade interna de acumulação de conhecimentos.

Os conhecimentos de origem externa podem ser formalizados, públicos ou privados, de acesso restrito ou não. Podem ser transferidos explicitamente em contratos de know-how ou de licenciamento de patentes. Outros, menos acessíveis ainda, são transferidos por compradores especializados, no momento em que especificam suas encomendas ou correspondem a resultados de pesquisa cooperativa. De toda forma, as empresas precisam ganhar competências para processar e integrar esses conhecimentos de diversas origens (FREEMAN, 1994).

A capacidade de aprender e gerenciar esses conhecimentos para melhor competir no mercado, determina, em grande parte, a diferença de desempenho diante da concorrência. Essa capacidade é essencial para se inserir numa economia caracterizada pela mudança tecnológica rápida e permanente, mas está condicionada às experiências da empresa, à sua cultura organizacional, sua memória operacional e sua estratégia de crescimento. É influenciada por diversos outros fatores, entre os quais:

- a qualificação dos recursos humanos;

- as características da demanda;

- a dinâmica competitiva do setor;

- as parcerias com usuários;

- os compradores ou fornecedores que detêm informações estratégicas;

- a disponibilidade de uma infra-estrutura pública de pesquisa e

- o sistema de financiamento dos investimentos na produção de conhecimentos avançados.

Esses fatores ultrapassam as fronteiras organizacionais das empresas e condicionam a materialização de um processo coletivo de acumulação de conhecimentos que permita acompanhar as mudanças tecnológicas do ambiente econômico em que elas atuam. Uma das maiores dificuldades das empresas é se capacitarem para localizar, obter e processar as informações disponíveis nesses diversos espaços organizacionais - como as outras empresas, as instituições especializadas em pesquisa, os centros técnicos de ensino e as exposições ou 
congressos -, para gerar os conhecimentos necessários ao desenvolvimento de novas soluções, em termos de concepção de produtos, reformulação de processos de fabricação ou modalidades de comercialização (FREEMAN, 1991).

\subsection{Importância das interações}

Segundo Lundvall (1992), se o recurso fundamental na economia moderna é o conhecimento, então o processo mais importante é o aprendizado. Este é essencialmente interativo e socialmente enraizado. Para entender sua dinâmica, precisamos identificar as modalidades utilizadas, o contexto institucional e cultural em que ele se concretiza e, especialmente, a intensidade das interações entre empresas e outras organizações que o favoreçam. As interações são estratégicas porque os conhecimentos necessários para inovar são gerados em outras organizações com as quais torna-se fundamental estabelecer canais de comunicação. Além das instituições de pesquisa, laboratórios ou centros técnicos - instituições especializadas na produção de conhecimentos -, empresas usuárias dos produtos ou fornecedores de insumos, peças e componentes são fontes permanentes de informações indispensáveis à inovação.

Da perspectiva da inovação, as empresas não podem se contentar em receber soluções prontas, desenvolvidas por outros, e serem meras receptoras passivas de tecnologia. Precisam incorporar, nas suas estratégias competitivas, a criação de canais (formais ou informais), pelos quais transitam fluxos de conhecimentos tão indispensáveis para a inovação quanto os fluxos de matérias-primas, bens ou serviços para as atividades de produção (FREEMAN, 1994). A busca da capacitação tecnológica impõe às empresas a obrigação de criar, preservar e valorizar as interações entre si.

Quando Freeman ou Lundvall raciocinam em termos de sistema nacional de produção e inovação, eles põem em evidência a dimensão estratégica das interações entre setores produtivos e entre empresas, e também o papel disseminador dos avanços tecnológicos atribuído a tais interações. Como alguns setores têm um maior dinamismo inovador, as interações garantem que os setores menos dinâmicos - que tendem a ser essencialmente usuários passivos de tecnologias desenvolvidas por outros - possam incorporar avanços tecnológicos gerados pelos mais dinâmicos (LUNDVALL, 1988).

\subsection{As especificidades setoriais}

Ademais, o processo de inovação é condicionado pelas especificidades setoriais, pela diversidade das fontes de conhecimentos, pelas oportunidades de inovação e pelas condições de apropriação dos benefícios da inovação. Esses elementos foram explicitados por Pavitt (1984) na formulação de uma taxionomia que diferencia quatro dinâmicas diferentes para a mudança tecnológica.

Em alguns setores, as empresas dependem fortemente de seus fornecedores de equipamentos. A inovação é o resultado das novas funções incorporadas em equipamentos cujo uso obriga a empresa a reorganizar o seu processo produtivo, buscar novos insumos, contratar recursos humanos com outras qualificações. A inovação se confunde com a instalação de novos equipamentos e as mudanças organizacionais que os acompanham.

Por outro lado, nas empresas cujo processo produtivo é de grande escala, tende-se a inovar na forma de melhorias incrementais no processo de fabricação, as quais dependem da capacidade de se montar uma base de competências internas em engenharia. O objetivo é otimizar e racionalizar a produção sem, entretanto, mudar radicalmente o processo.

Para as empresas fornecedoras de equipamentos avançados, o processo de inovação visa oferecer novos produtos com novas funções que irão atender a compradores ou usuários com demandas de maior complexidade. Nesse caso, é essencial para os fabricantes cooperar com os usuários de maneira a obter informações sobre o desempenho dos equipamentos e as suas necessidades específicas. Precisam também interagir com instituições de pesquisa que são as geradoras de conhecimentos novos, indispensáveis para desenvolver novos equipamentos que incorporarão os resultados das pesquisas. 
Finalmente, em setores industriais de tecnologia de ponta (computação, indústria farmacêutica, biotecnologia) as inovações são diretamente relacionadas aos avanços científicos e à aplicação industrial de novos paradigmas tecnológicos. Os investimentos em pesquisa e desenvolvimento realizados internamente são indispensáveis, bem como as interações regulares com instituições de pesquisa.

\subsection{Padrão de inovação e ciclo de vida do produto}

Finalmente, a maneira de uma unidade produtiva inovar varia em função do posicionamento de suas atividades. Isso implica um espectro de situações que vai da colocação no mercado de volumes limitados de produtos novos - cujo processo de fabricação ainda está submetido a redefinições e mudanças - até a grande empresa com um processo de produção, totalmente definido e estabilizado, de produtos que não evoluem mais tecnicamente (ABERNATHY e UTTERBACK, 1978). As estratégias comerciais e as características organizacionais das firmas variam em função desse posicionamento da unidade produtiva considerada, enquanto as inovações mudam de natureza, intensidade e objetivos. Mudanças na concepção do produto e na definição do processo de fabricação, bem como na organização, vão se combinar com pesos diferentes ao longo do ciclo de vida dos produtos.

Inicialmente, são as inovações de produto que envolvem mudanças mais radicais em relação ao que já está disponível no mercado, que apresentam maiores incertezas quanto ao desempenho do produto para os usuários. Por outro lado, oferecem maiores possibilidades de lucro, devido à importância dos benefícios trazidos aos usuários. A incorporação de novas funções no produto desenvolvido atende melhor às necessidades dos compradores, os quais aceitarão pagar preços altos, já que os bens novos permitem ganhos significativos diante dos concorrentes. A pequena unidade de produção, orientada para responder a necessidades emergentes, precisa de uma estrutura organizacional interna flexível e que favoreça as interações com instituições de pesquisa e com os usuários interessados. Na fase inicial de geração de novos produtos, a busca por conhecimentos provenientes de centros de pesquisa e a coleta de informações junto aos usuários são estratégicas e devem ser asseguradas pelas interações e práticas de cooperação.

Uma vez eliminadas as incertezas e bem definido o processo de fabricação, não haverá mais necessidade de mudar o processo de produção, e as inovações futuras serão incrementais, visando racionalizar o processo de produção - aumentando a produtividade para diminuir os custos - e abrir a possibilidade de competir oferecendo preços menores. As melhorias incrementais resultam da adoção de procedimentos e de rotinas mais eficientes. Nesse contexto, a opção entre inovação de produto e inovação de processo não resulta de uma escolha aleatória, mas das características da demanda por produtos novos e do processo de manufatura efetivamente em operação na empresa.

São essas reflexões sobre a natureza do processo de inovação que servirão de referencial para interpretar os resultados da pesquisa do IBGE e avaliar a natureza e a intensidade das atividades tecnológicas desenvolvidas pelas empresas industriais brasileiras. Devido ao número de empresas pesquisadas, os dados coletados são de grande valor para compreender melhor a base da capacidade de inovação da indústria brasileira.

\subsection{As atividades inovadoras em países de industrialização recente}

Para recorrer a modelos de interpretação do processo de inovação que tem por foco principal o comportamento das empresas, é necessário considerar o contexto econômico em que ele está inserido. Diversos autores, desde os anos 1980 (BELL, 1984; KATZ, 1984 e 1985; LALL, 1992; BELL e PAVITT, 1992 e 1993), analisaram as peculiaridades do processo de industrialização em economias intermediárias e as consequiências sobre a intensidade e a velocidade da aquisição de competências tecnológicas.

A década de 1970 foi marcada por intensa transferência de tecnologia dos países industrializados para países em desenvolvimento, em particular da América Latina e da Ásia, mediante licenciamento de know-how e a instalação de empresas multinacionais. Essas modalidades foram amplamente criticadas por serem incapazes de romper com a dependência tecnológica das economias a que se destinavam. Alguns autores procuraram avaliar melhor os impactos dos fluxos de tecnologia. 
Katz (1984 e 1985) analisa a origem, a natureza e os impactos das mudanças tecnológicas na formação da base industrial de países de industrialização recente como Chile, Brasil, Argentina ou México. O autor constata que a eficiência na utilização das novas tecnologias de origem externa varia muito de uma empresa para a outra (uma pode ser inovadora e melhorar seu posicionamento no mercado; outra, que não inova, acaba desaparecendo) em função do seu setor de atividades, do mercado onde atua, de sua capacidade de definir estratégias e, também, em função de fatores macroeconômicos (políticas industriais, cambiais ou de comércio exterior). Katz mostra que as empresas, para assimilar as tecnologias novas, passam por vários estágios de aprendizado (engenharia de produto, design, controle e planejamento da produção).

Bell (1984) apresenta uma análise semelhante. Mostra que toda aquisição de tecnologia exige esforços de adaptação e adequação às condições específicas de funcionamento de cada empresa e ao ambiente mercadológico e socioeconômico. Segundo seu raciocínio, a capacitação tecnológica corresponde à aquisição de competências e conhecimentos técnicos, a partir de um processo de aprendizado, tanto dos indivíduos quanto das organizações produtivas, de maneira coletiva. As habilidades dos indivíduos resultantes das experiências de uso da tecnologia e os conhecimentos codificados adquiridos externamente permitem gerenciar de maneira mais eficiente a tecnologia utilizada. A partir de um certo nível de competências, é possível realizar pequenas melhorias incrementais. Contudo, o autor ressalta que esse aprendizado é um processo complexo e lento que não ocorre automaticamente. Pelo contrário, requer que as empresas adotem uma estratégia de gestão dos recursos tecnológicos, de investimentos específicos para qualificação dos recursos humanos, da contratação de consultores e da alocação de recursos para realizar atividades que possibilitem a inovação.

Em artigos mais recentes, Bell \& Pavitt (1992 e 1993) retomam essa análise e detalham as etapas e o conteúdo do aprendizado que está na base do processo de acumulação de conhecimento tecnológico em países de industrialização recente. Em primeiro lugar, eles salientam o fato de que é muito difícil, senão impossível, diferenciar claramente o processo de inovação do processo de difusão da tecnologia. Este é acompanhado de mudanças incrementais e adaptativas e de melhorias que permitem às empresas alcançarem novos critérios de performance. Na primeira fase da industrialização, ocorre uma acumulação tecnológica que tem origem na instalação dos fatores de produção e no estabelecimento de relações entre setores e empresas industriais. Na segunda fase, a acumulação toma a forma de aquisição de know-how, de uma capacidade de concepção de bens de capital e equipamentos pesados, de reverse engeneering e de pesquisa e desenvolvimento imitativa.

Os autores reafirmam que a acumulação tecnológica ocorre dentro das empresas industriais, mas depende da existência de um sistema nacional de produção, resultando da aquisição de tecnologias externas integradas a capacidades locais das empresas, investimentos importantes em educação e em pesquisa acadêmica, incentivos econômicos para imitar e inovar, demanda crescente por produtos mais avançados e também de instituições e políticas específicas para apoiar a acumulação técnica nas firmas.

Nessa abordagem, nota-se que o processo de capacitação é indissociável da formação de um sistema de produção, embora a capacitação não seja consequiência automática da implantação de capacidades físicas de produção. A capacitação é difícil porque, por um lado, os conhecimentos são em parte tácitos, mas também porque são bastante diversos os fatores que levam as empresas a mudarem seus produtos, processos, procedimentos ou rotinas. No entanto, é claro que, mesmo para implantar mudanças tecnológicas menores, as empresas precisam ter acumulado experiências e habilidades específicas. Além disso, precisam que outras instituições, de treinamento ou pesquisa, lhes ofereçam apoio para desenvolverem novas soluções ou melhorias incrementais. Por fim, é indispensável que disponham de recursos humanos qualificados e especializados.

Uma análise parecida é apresentada por Lall (1992), que afirma que as concepções tradicionais sobre atividades tecnológicas desconhecem a natureza peculiar e os custos do aprendizado tecnológico. De acordo com tal ponto de vista a inovação é uma atividade totalmente distinta do esforço para adquirir domínio da tecnologia ou para adaptá-la a condições locais diferentes. Essas abordagens estabelecem uma separação conceitual entre inovação e produção e entre inovação e difusão das inovações. Consequientemente, consideram que as inovações ocorrem todas nos países avançados. Nos países de industrialização recente, entretanto, os esforços tecnológicos endógenos ocupam um lugar central e visam ao domínio das tecnologias adquiridas, a adaptá-las às 
especificidades das condições de produção e do mercado e a melhorá-las, para que se consiga melhor retorno e vantagens competitivas.

Concluindo, todos esses autores apresentam uma definição do processo de inovação que valoriza as atividades tecnológicas baseadas no processo de aprendizado e no domínio gradual da tecnologia. A reflexão é retomada pelos autores do Manual de Bogotá ${ }^{5}$ que consideram o conceito de inovação utilizado no Manual de Oslo (OECD, 2000) por demais restritivo para analisar os esforços pela inovação nas unidades produtivas em economias de industrialização recente. Esses autores propõem o conceito de atividades inovadoras, o qual inclui monitoramento, avaliação, adoção e adaptação de tecnologia pelas empresas produtivas. Igualmente sugerem que se dê um peso maior à noção de acumulação inicial de capacidades (para absorver os conhecimentos), ao processo de difusão e aos esforços de adaptação e de melhorias incrementais. Além disso, eles reconhecem como essenciais as mudanças na organização do processo de produção e comercialização que, contudo, não costumam ser consideradas inovações tecnológicas no sentido mais estrito da palavra. São essas atividades, portanto, que determinam o ritmo e a intensidade das mudanças tecnológicas na estrutura produtiva.

Essas reflexões sobre a natureza do processo de inovação servirão de referencial para interpretar os resultados da pesquisa do IBGE e avaliar a natureza e a intensidade das atividades tecnológicas desenvolvidas pelas empresas industriais brasileiras. É possível perceber que muitas dessas análises orientaram a formulação das perguntas e foram incorporadas no questionário da Pintec. Devido ao número de empresas pesquisadas, os dados coletados oferecem uma contribuição importante para se conhecer melhor a base da capacidade inovadora e o comportamento da indústria brasileira.

\section{Panorama da capacidade de inovação da indústria brasileira}

As informações apresentadas pela Pintec 2000 são relacionadas ao comportamento tecnológico das empresas, levando em consideração diferenças por setor de atividades e por tamanho. O universo analisado ${ }^{6}$ é bastante abrangente: compreende 72.005 empresas com, no mínimo, 10 empregados e que representam mais de 32 setores industriais. Essa variável é definida a partir do número de pessoas empregadas e não pelo valor do faturamento. Do total pesquisado (Tabela 1), $89 \%$ das empresas podem ser consideradas pequenas, com menos de 100 pessoas ocupadas, $9 \%$, médias (tendo de 100 a 250 pessoas) e $5 \%$, grandes.

\section{Tabela 1}

Participação das empresas nos resultados da pesquisa segundo o tamanho

\begin{tabular}{lccc}
\hline $\begin{array}{c}\text { Número de pessoas } \\
\text { ocupadas }\end{array}$ & $\begin{array}{c}\text { Participação na } \\
\text { amostra (\%) }\end{array}$ & $\begin{array}{c}\text { Participação no } \\
\text { total das empresas } \\
\text { que inovaram (\%) }\end{array}$ & $\begin{array}{c}\text { Participação das } \\
\text { empresas que inovaram } \\
\text { na sua categoria (\%) }\end{array}$ \\
\hline De 10 a 29 & 66 & 52 & 25,2 \\
De 30 a 49 & 13 & 14 & 33,3 \\
De 50 a 99 & 10 & 14 & 43,0 \\
De 100 a 249 & 6 & 10 & 49,3 \\
De 250 a 499 & 3 & 5 & 56,7 \\
500 ou mais & 2 & 5 & 75,6 \\
\hline
\end{tabular}

Fonte: IBGE (Pesquisa Industrial Inovação Tecnológica - Pintec 2000, a partir das tabelas 19.1 e 20.1).

\footnotetext{
${ }^{5}$ O Manual de Bogotá foi redigido por economistas da Colômbia e da Argentina, a pedido da Red Iberoamericana de Indicadores de Ciencia y Tecnología (Ricyt)/Organização dos Estados Americanos (OEA)/Programa Cyted, em 2001. O Manual de Oslo da OECD deu origem ao questionário Pintec do IBGE.

${ }^{6}$ Segundo o Cadastro Central de Empresas do IBGE, em 2000, o Brasil tinha 4.124.343 empresas ativas; isto é, entidades empresariais, órgãos da administração pública e outras entidades privadas sem fins lucrativos. Desse total, $10 \%$ correspondia a empresas do setor de transformação.
} 


\subsection{Caracterização das inovações implementadas e das empresas inovadoras}

O estudo informa que $31,5 \%$, ou seja, menos de um terço do total das empresas pesquisadas, desenvolveram produtos e/ou implementaram processos tecnologicamente novos ou substancialmente aprimorados no período 1998-2000. Embora, em termos absolutos, 22.698 empresas terem desenvolvido um processo de inovação não seja um número desprezível, em termos relativos, a falta de dinamismo tecnológico continua caracterizando a base industrial brasileira. A prática da inovação está longe de ser generalizada. As empresas maiores tendem a inovar mais. No entanto, como o número de empresas brasileiras de grande porte é pequeno, o comportamento das pequenas empresas passa a ter um peso maior no resultado final.

Uma análise mais detalhada permite caracterizar o foco das atividades inovadoras das empresas: 6,3\% delas desenvolveram inovações de produto, 13,94\%, inovações de processo e 11,28\%, inovações de produto e processo (Figura 1). A tipologia tradicional - que diferencia a inovação de produto da inovação de processo incorporou mais recentemente a categoria da inovação organizacional, uma vez que as duas primeiras são fortemente interligadas e têm como impacto a necessidade de promover a terceira. Embora os três tipos de mudança tendam a ocorrer em conjunto, as modalidades inovadoras, os formatos organizacionais e os objetivos competitivos são diferentes, dependendo do tipo de inovação que está sendo desenvolvido.

Deve ser observado que as empresas de maior porte tendem a realizar ao mesmo tempo inovações de produto e processo, enquanto as de menor porte implementam apenas um tipo de inovação, seja de produto ou de processo. Mas essa diferenciação não é sempre fácil de ser estabelecida. Freqüentemente, pequenas modificações incrementais num produto não levam necessariamente a mudanças no processo de fabricação. De maneira geral, contudo, as grandes empresas têm melhores condições de articular entre si as diversas variáveis (acesso ao conhecimento, a financiamento, capacidade organizacional, estratégia de comercialização) que caracterizam a complexidade do processo de inovação.

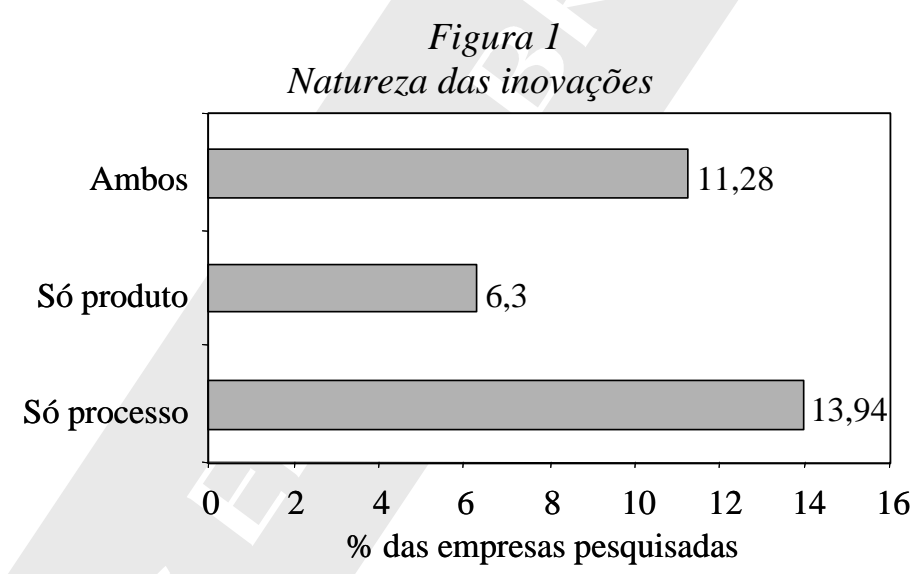

Fonte: IBGE (Pesquisa Industrial Inovação Tecnológica - Pintec 2000, a partir da tabela 2).

Além disso, 18,3\% das empresas tentaram inovar, mas não tiveram êxito. A razão mais freqüentemente apontada pelas empresas para esse limitado desempenho inovador é a fraca resposta dos compradores ou usuários; isto é, o comportamento de um mercado que não apresenta demanda por inovações. Essa falta (ou insuficiência) de demanda por produtos novos tem sua origem fora do espaço de decisão da empresa individual. É uma característica do ambiente econômico nacional que, fora algumas exceções, ainda não conseguiu plenamente assimilar o fato de que o conhecimento e a mudança tecnológica são os novos parâmetros da competitividade, e, por conseguinte, reconhecer a absoluta prioridade da capacitação tecnológica e da inovação.

Quando se investiga a relação entre tamanho da empresa e capacidade de inovar, algumas variações importantes aparecem. As empresas maiores adotam práticas inovadoras mais intensas. A taxa de inovação é de 75,6\% para as empresas de mais de 500 empregados; portanto, muito superior à taxa de cerca de $30 \%$ paras as empresas pequenas. A capacidade de financiamento pode ser um dos fatores de maior peso para explicar a 
diferença, já que, de modo geral, as grandes empresas dispõem de maiores recursos financeiros, humanos, organizacionais e de maior capacidade de acesso ao mercado e a fontes de conhecimento. Elas são inseridas em mercados mais abertos à competição, onde as pressões dos concorrentes obrigam a melhorar e a modernizar o processo produtivo interno e, além disso, interagem mais com outras empresas, conseguindo ter mais acesso às novas tecnologias.

Devem ser mencionadas ainda duas características importantes das práticas inovadoras. Primeiro, as inovações de processo são mais numerosas que as inovações de produto, e a principal modalidade de mudança do processo de fabricação é a compra de máquinas e equipamentos. Isso confirma que ainda perdura a preferência pela tecnologia madura, já testada e incorporada em bens de capital. Equipamentos e bens de capital funcionam como meio principal de disseminação dos avanços tecnológicos. As inovações de processo correspondem a uma modernização tecnológica que pode até levar a pequenos rearranjos organizacionais ou a pequenas mudanças no desenho do produto. A predominância dessa modalidade confirma que a trajetória da indústria brasileira continua fortemente dependente de fontes externas de tecnologia e que as empresas permanecem essencialmente receptoras de tecnologias desenvolvidas por outros; em geral, de fora do sistema produtivo nacional. Essa característica já tinha sido apontada no estudo da Confederação Nacional da Indústria (CNI) e da Comissão Econômica das Nações Unidas para a América Latina (Cepal), que analisou as empresas brasileiras no período 1995-1999 (CNI-CEPAL 1997, CNI 2002) e se mantém, com pequenas alterações, qualquer que seja o porte da empresa.

O segundo aspecto é que, em coerência com a característica apontada anteriormente, a novidade diz respeito essencialmente ao ambiente interno da própria empresa que implementa a inovação (Tabela 2). A novidade é muito limitada ou inexistente quando o novo produto é comparado àqueles equivalentes encontrados no mercado. É igualmente limitada ou inexistente quando o novo processo é comparado com a organização da produção em outras empresas ou em outros sistemas produtivos. Aliás, vale notar que, para novos produtos, em mais de $70 \%$ dos casos, a própria empresa é a única responsável pelo desenvolvimento da inovação. Isso significa que a idéia de inovação não veio em resposta a uma demanda identificada no mercado, nem foi desenvolvida em cooperação com outra organização.

Tabela 2

Grau de novidade das inovações

(empresas que inovaram)

\begin{tabular}{lcc}
\hline & Produto & Processo \\
\hline Novo para a empresa & $81,8 \%$ & $92,2 \%$ \\
\hline Novo para o mercado & $18,2 \%$ & $7,8 \%$ \\
\hline
\end{tabular}

Fonte: IBGE (Pesquisa Industrial Inovação Tecnológica - Pintec 2000, a partir da tabela 4).

Dos $18 \%$ do total de empresas que implementaram produtos novos ou substancialmente aprimorados, apenas $4 \%$ afirmaram que esse produto era novo para o mercado nacional. No caso das inovações de processo, $25 \%$ das empresas inovaram, mas somente $3 \%$ implementaram processos novos em relação ao mercado nacional, confirmando a percepção de que as inovações de processo correspondem à compra de máquinas sem que haja redefinição da concepção do produto ou do seu processo de fabricação. A modernização significa uma atualização técnica sem que haja um esforço inovador baseado na busca de soluções diferentes.

Entretanto, a diversidade de demandas no mercado em que atua a empresa funciona como um estímulo à capacidade de inovação. As taxas de implementação de inovação se reduzem consideravelmente quando o mercado de referência da empresa é exclusivamente nacional. Há uma relação positiva entre o elemento "novidade" e a atuação internacional das empresas. De modo geral, as empresas instaladas no mercado externo são mais inovadoras, provavelmente, porque têm acesso a mais fontes de informação, são submetidas a maiores pressões por parte dos concorrentes e conseguem aproveitar melhor as interações com parceiros externos. 


\subsection{A inovação conforme o setor de atividades}

Segundo Pavitt (1984), quanto à capacidade de inovação, há importantes diferenças no comportamento das empresas. Isso está condicionado às características do processo de produção do setor e do mercado em que elas operam. Alguns setores tendem a ser receptores de inovações desenvolvidas por outros. Há segmentos em que as empresas devem necessariamente investir em atividades internas de pesquisa e desenvolvimento para poder inovar. São os setores estreitamente baseados nos avanços científicos, como o de biotecnologia ou o de instrumentação; ou intensivos em tecnologia como o de informática, o de telecomunicações ou o de material de transportes. Entretanto, os dados apresentados mostram um quadro relativamente homogêneo: para todos os setores, a principal modalidade de inovação é a compra de equipamentos. Isso significa que grande parte das empresas brasileiras, qualquer que seja o setor, recebem tecnologia de fontes externas (outras empresas, outros setores ou outras economias) mesmo quando seria de se esperar um esforço tecnológico interno mais intenso. Provavelmente, algumas empresas, individualmente, fazem esse esforço, mas, a nível setorial, esse comportamento isolado não causa impacto sobre o resultado global.

Outras especificidades setoriais podem ser identificadas. Os segmentos de maior dinamismo inovador correspondem, por ordem de importância, ao de fabricação de máquinas para escritório e equipamentos de informática (68\%), material eletrônico básico (63\%), aparelhos e equipamentos de comunicações (62\%), equipamentos de instrumentação médico-hospitalar, instrumentos de precisão e óticos, equipamentos para automação industrial, cronômetros e relógios $(60 \%)$ e o de produtos farmacêuticos (47\%). Esses setores exercem uma liderança tecnológica, atuando como difusores de inovações para outros segmentos ou empresas. Ao examinar os gastos com atividades inovadoras, é constatado que o setor de produção de bens de capital tradicionalmente considerado difusor do progresso técnico - apresenta ao mesmo tempo, o maior percentual de gastos com atividades inovadoras em relação à receita, e, não por acaso, um desempenho inovador acima da média.

As menores taxas de inovação são encontradas nas atividades de produção intensivas em recursos naturais e mão-de-obra. Isso leva a pensar que a competitividade desses setores permanece ligada a vantagens tradicionais, como baixos custos do trabalho ou proximidade das fontes de matéria-prima, deixando de lado vantagens relacionadas à capacidade de utilizar tecnologias mais avançadas.

\subsection{Da modernização tecnológica aos investimentos em pesquisa}

Para perguntas de caráter qualitativo, a Pintec ofereceu às empresas diversas alternativas de resposta e a possibilidade de atribuir um peso a cada uma. ${ }^{7}$ Para a maior parte das empresas (77\% daquelas que inovaram), a atividade inovadora de maior importância corresponde à aquisição de máquinas e equipamentos novos (Figura 2). A opção privilegiada é a compra de tecnologia incorporada às máquinas e equipamentos. A aquisição, implementação e operação dos novos equipamentos - isto é, adoção de tecnologia desenvolvida externamente à empresa ou ao setor - continua sendo a forma tradicional de incorporar mudanças tecnológicas na produção, correspondendo a mais de $50 \%$ do total dos gastos com inovação, independentemente do tamanho da empresa. Em qualquer economia, a compra de equipamentos é para as empresas a forma mais comum de acesso ao progresso técnico, mas é aquela que menos favorece a geração de conhecimentos, a ampliação da base tecnológica interna e o aprendizado. Essa constatação é particularmente preocupante, visto que a busca da competitividade interna e internacional não pode deixar de tomar como referência a formação de uma capacidade de inovação crescente, que exige investimentos em pesquisa.

Apesar de ser pouco propícia à acumulação de conhecimentos avançados, a aquisição de equipamentos novos requer a definição de um projeto industrial e o treinamento dos recursos humanos. O treinamento é apontado como a segunda maior atividade (22\%), mas, surpreendentemente, absorve a menor fração dos gastos com

Para essas perguntas, o ranking corresponde ao grau de importância atribuída (alta, média ou baixa). Para simplificar a leitura dos resultados, as percentagens apresentadas neste trabalho levam em consideração unicamente às respostas da categoria "alta importância". 
inovação (1,8\%). Por outro lado, supõe-se que a mensuração dos gastos é difícil, já que em muitos casos esses custos são incorporados ao valor da compra das máquinas, quando o fornecedor se responsabiliza pelo treinamento ou quando este ocorre on the job, sem necessidade de parar a produção e de separar os custos do treinamento dos da produção.

\section{Figura 2}

Atividades inovadoras consideradas de maior importância pelas empresas que inovaram (\% das respostas)

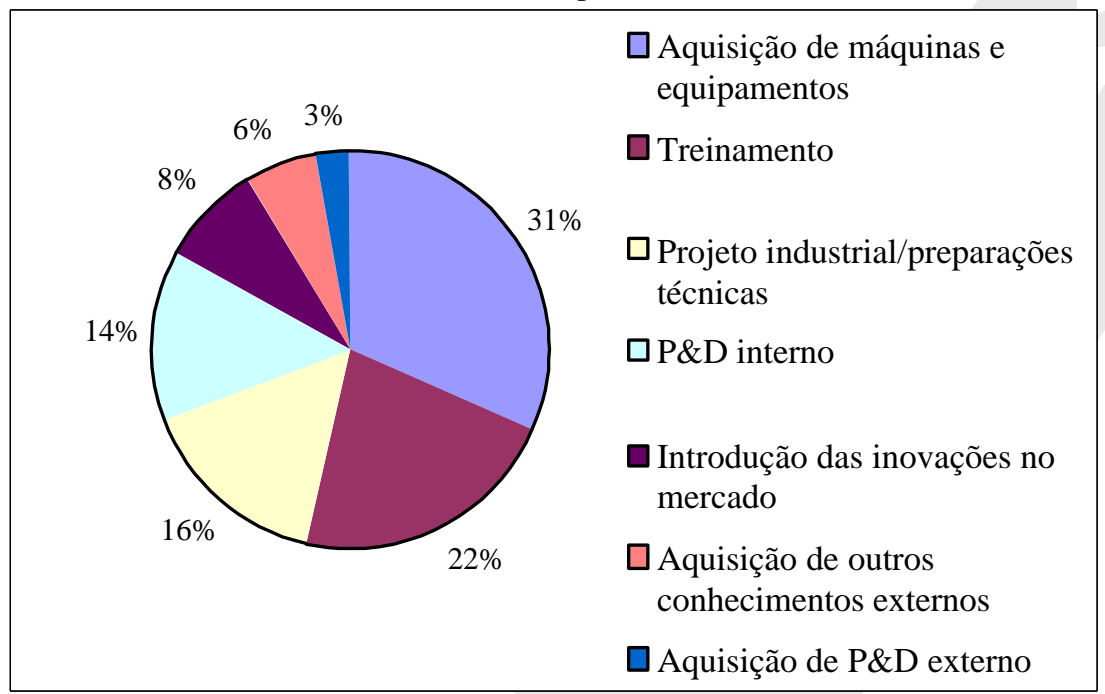

Fonte: IBGE (Pesquisa Industrial Inovação Tecnológica - Pintec 2000, a partir da Tabela 13).

Por ordem de importância, a ordenação dessas atividades traduz avanços em termos de organização da produção e de capacidade de avaliar as tecnologias disponíveis no mercado. No entanto, confirma a concepção pouco dinâmica do que seja mudança tecnológica, com as atividades internas de pesquisa chegando em quarto lugar. São modalidades que tornam possível aprender a operar sistemas técnicos novos, mas, ao mesmo tempo, caracterizam um comportamento relativamente passivo. Dificilmente permitirão ampliar a capacidade de competir das empresas. Apenas garantem a atualização tecnológica, de acordo com padrões nacionais ou internacionais.

A inovação é um processo complexo de busca de soluções que não pode ser entendido como compra de equipamentos novos. Para definir uma verdadeira estratégia tecnológica, é preciso reunir vários componentes; e não há dúvida de que uma maior capacitação tecnológica passa por outras modalidades de incorporação e gestão da tecnologia. A capacidade de desenvolver novas tecnologias de produção requer investimentos significativos em pesquisa e desenvolvimento interno, projetos de pesquisa conjunta com instituições especializadas e contratação de recursos humanos capacitados.

Os investimentos em pesquisa e desenvolvimento interno são os que mais permitem gerar conhecimentos novos, os quais poderão levar a inovações mais valiosas, de maior impacto, trazendo efetivamente um diferencial na competição. É um fator decisivo para desenvolver produtos realmente novos, não só para a empresa, mas também para o mercado nacional e internacional. Obviamente, isso é uma atividade arriscada cujos resultados são sempre incertos, já que em muitos casos, as novas tecnologias desenvolvidas não são facilmente transformadas em produtos ou serviços bem sucedidos no mercado. Em alguns casos, o retorno do investimento em pesquisa poderá ser protegido pelo depósito de patentes. Entretanto, é notória a debilidade dos investimentos em pesquisa e desenvolvimento por parte das empresas brasileiras, o que é confirmado pelos 
resultados da Pintec 2000. As empresas inovadoras colocam essa atividade em quarta prioridade no ranking das atividades inovadoras de maior importância, e os gastos relacionados correspondem a $16 \%$ do total. O estudo contabiliza somente 41.000 pessoas $^{8}$ realizando atividades de pesquisa. Menos da metade dessas pessoas tem nível de educação superior e se dedica em tempo integral à pesquisa e desenvolvimento. Uma conseqüência dessas limitações aparece claramente: somente $8 \%$ das empresas inovadoras entraram com pedido de patentes (Figura 3).

\section{Figura 3}

Número de empresas que inovaram com patentes requeridas ou em vigor

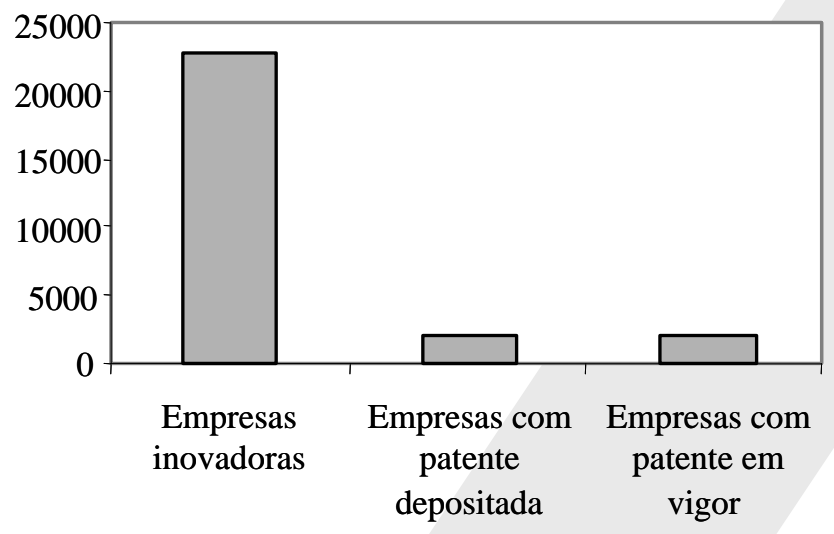

Fonte: IBGE (Pesquisa Industrial Inovação Tecnológica - Pintec 2000, a partir da tabela 6).

A proporção de empresas que realizam pesquisa e desenvolvimento de maneira contínua aumenta à medida que cresce o tamanho da empresa. Nas empresas menores, apenas $28 \%$ delas realizam pesquisa e desenvolvimento de maneira contínua, enquanto nas empresas maiores, esse percentual é de $80 \%$, e os gastos em pesquisa e desenvolvimento representam $75 \%$ do total dos gastos. Quanto à aquisição de resultados de pesquisa e desenvolvimento realizada por outra instituição, corresponde a 2,8\% dos gastos e tem relevância somente para $25 \%$ das empresas que inovaram, dado que confirma a debilidade das relações entre pesquisa e indústria.

\subsection{Fontes externas de conhecimento e informação e relações de cooperação}

A análise das fontes de informação é importante para entender o processo de inovação, já que, ao identificar a instituição de origem dos conhecimentos utilizados no processo de inovação, podemos avaliar a capacidade das empresas de buscarem conhecimentos externos através de relações de cooperação com outras organizações. Para isso, é preciso estruturar uma rede de relacionamento com diversas organizações e instituições, o que permite ter acesso a informações que não podem ser facilmente encontradas no mercado, como também a conhecimentos especializados que são gerados em instituições de pesquisa. A escolha dessas fontes externas depende da estratégia de inovação e da capacidade das empresas de absorver e combinar tais informações.

A modalidade deveria permitir que fosse compensada a debilidade dos investimentos em pesquisa e desenvolvimento interno, como também avaliar a competência das empresas para gerenciar uma rede de parceiros e de interações. Para inovar e aumentar a capacidade de competir com os concorrentes, melhorando o desempenho e a eficiência na realização das operações produtivas, as empresas precisam reunir um conjunto de conhecimentos e de habilidades bastante diferentes daqueles que são exigidos numa gestão de negócios mais tradicional e que costuma recorrer ao mercado na busca de inovações desenvolvidas por outros.

Segundo as Estatísticas do Cadastro Central de Empresas 2001 (IBGE 2003), em 2001 havia 450000 empresas industriais ocupando 6 milhões de pessoas. 
As fontes de informação utilizadas pelas empresas variam muito (ver Figura 4). As citadas com mais frequiência estão relacionadas com as atividades de mercado das próprias empresas: os fornecedores (66\%), os clientes e consumidores $(60 \%)$ e os concorrentes (48\%). As feiras e exposições se destacam (62\%) como fontes de informações setoriais. Em seguida, são mencionados encontros, conferências, publicações especializadas e redes de informações informatizadas. As fontes de informações especializadas, como a consultoria ou as universidades ou instituições de pesquisa, são as menos citadas, apesar de serem as que assegurariam conhecimentos mais avançados.

\section{Figura 4}

Fontes de informações de maior importância segundo as empresas inovadoras

(ranking por número de respostas)

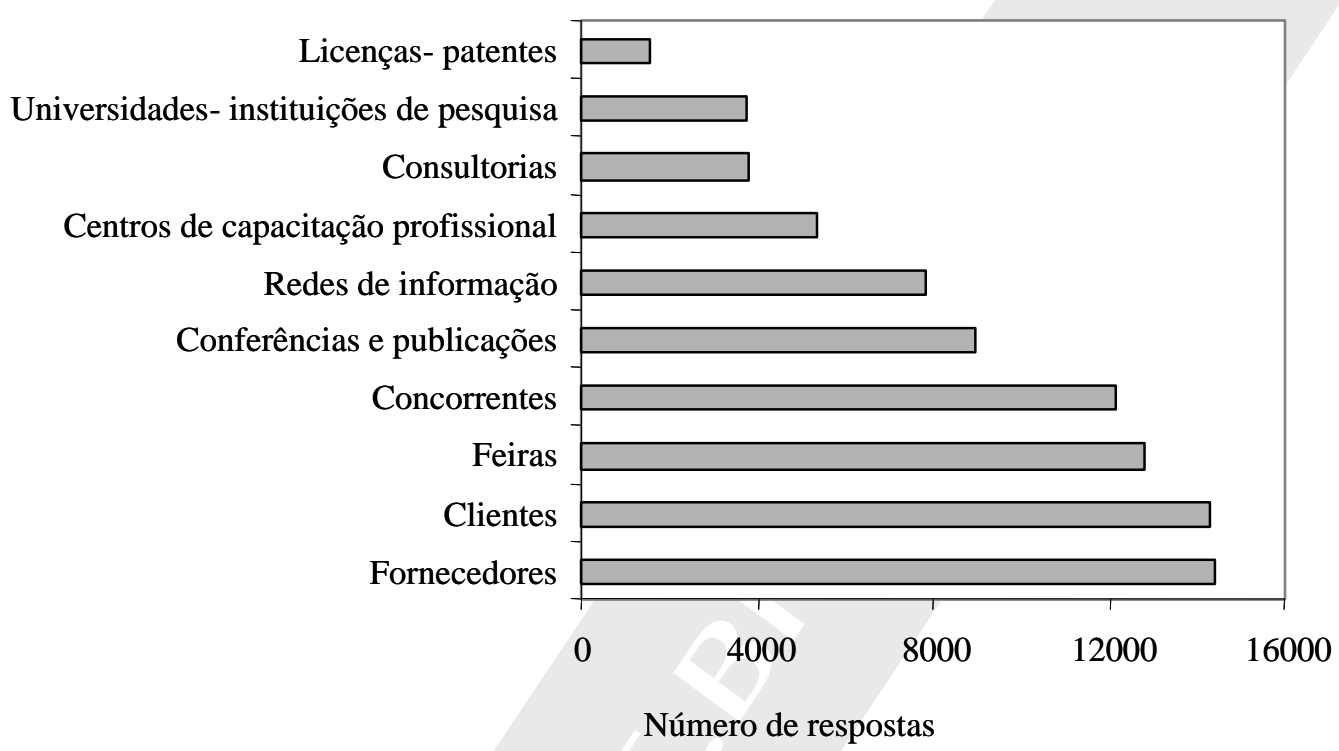

Fonte: IBGE (Pesquisa Industrial Inovação Tecnológica - Pintec 2000, a partir da tabela 22)

As grandes empresas tendem a combinar informações a partir de uma maior diversidade de fontes. Mas de maneira geral, não é freqüente a aquisição de conhecimentos gerados por fontes externas. Poucas empresas (menos de 4.000) buscam acesso a resultados de atividades de pesquisa desenvolvidas por outras organizações, licenças, patentes ou know-how. São bastante raras aquelas que buscam informações junto a universidades ou institutos de pesquisa.

O quadro é muito parecido quando se analisa as práticas de cooperação. As interações com fornecedores ou compradores têm um papel fundamental para o desenvolvimento de produtos ou processos novos, na medida em que elas promovem a disseminação das informações e das novas tecnologias e alimentam o processo de aprendizado. Apenas 2.505 empresas inovadoras declaram cooperar com outras empresas ou instituições; aliás, quase exclusivamente nacionais. Somente $11 \%$ das empresas inovadoras tinham arranjos de cooperação com outras organizações. Essa proporção aumenta com o tamanho da empresa: está em $38 \%$ para as empresas maiores, mas somente de 7,4\% para as pequenas. Essa percentagem baixa traduz o isolamento das organizações que ainda não se conscientizaram da importância estratégica das relações de cooperação para o processo de inovação. Os parceiros mais freqüentes são os fornecedores (55\%) e os clientes ou usuários (45\%) (ver Figura $5)$.

A capacidade de inovar é fortemente dependente da capacidade de buscar conhecimentos novos. Por isso, é fundamental identificar a freqüência das relações de cooperação com instituições especializadas na produção do conhecimento, bem como a natureza das atividades desenvolvidas pelas empresas para inovar e determinar quais as modalidades utilizadas pelas estas para ter acesso ao conhecimento ou para produzi-lo. Extremamente 
limitadas são as relações com instituições de pesquisa, mencionadas por 845 empresas. As empresas parecem pouco interessadas na cooperação com instituições que são fontes de conhecimentos realmente avançados e que possibilitam inovações mais radicais.

\section{Figura 5}

Parceiros mais freqüentes para a cooperação segundo as empresas que inovaram (ranking pelo número de respostas)

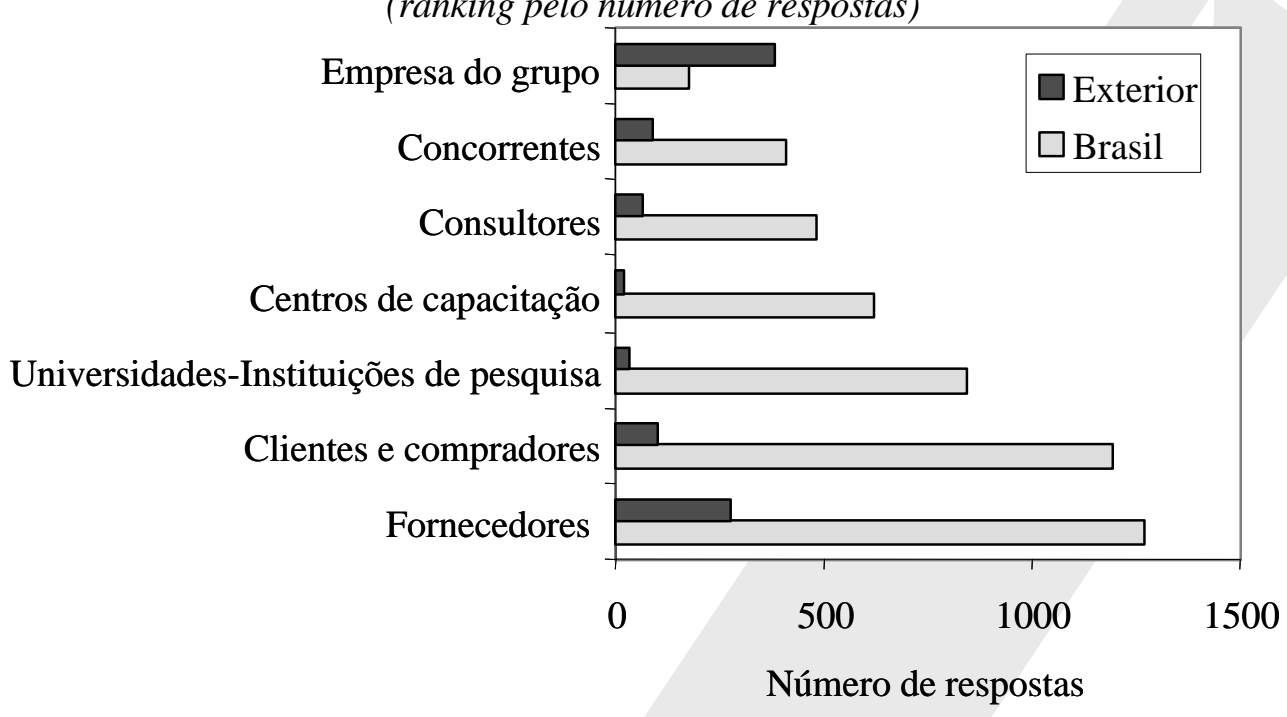

Fonte: IBGE (Pesquisa Industrial Inovação Tecnológica - Pintec 2000, a partir da tabela 23).

Pelas respostas apresentadas, chega-se à conclusão de que as principais fontes de conhecimento das empresas são internas. Paralelamente, a constatação de que a existência de uma área de pesquisa e desenvolvimento nas empresas não é muito freqüente e que os investimentos são limitados confirma o caráter informal e precário dessa atividade. Conclui-se que a capacidade interna de gerar novos conhecimentos é tão limitada quanto a busca de conhecimentos avançados desenvolvidos externamente, comportamento que constitui a raiz da extrema fragilidade da base tecnológica da indústria brasileira. Para a maior parte das empresas, as vantagens de mercado não são sustentadas por vantagens competitivas baseadas no domínio de conhecimentos avançados, parâmetro principal para a competitividade de uma economia.

\subsection{As motivações}

A necessidade de resistir às pressões dos concorrentes e a perspectiva de ganhos no mercado são os principais motivos para implementar produtos e/ou processos tecnologicamente novos ou substancialmente aprimorados. As inovações são apresentadas como tendo impacto tanto em nível do produto quanto do processo e da comercialização. As empresas consideram, em primeiro lugar, a melhoria da qualidade do produto, item que condiciona diretamente seu posicionamento no mercado e a capacidade de competir. As expectativas mais significativas para justificar o esforço por inovação (Figura 6) correspondem à manutenção e ampliação da participação no mercado, ao aumento da capacidade produtiva e da flexibilidade de produção e, também, à redução dos custos do trabalho. Contudo, menos de um quarto das empresas que inovaram buscavam abrir novos mercados; resultado coerente com o limitado grau de novidade das mudanças adotadas, como comprovado anteriormente, mas que expressa bem a timidez das estratégias de inovação. 


\section{Figura 6}

Impactos de maior importância para as empresas que inovaram

(\% de respostas)

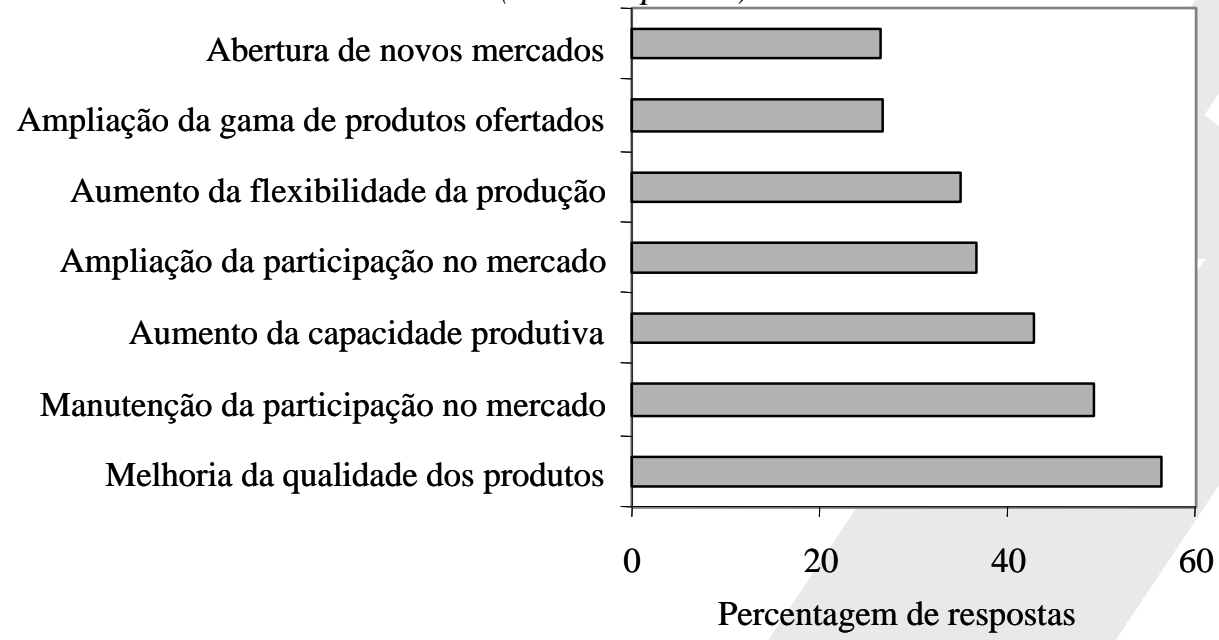

Fonte: IBGE (Pesquisa Industrial Inovação Tecnológica - Pintec 2000, a partir da tabela 19).

É interessante notar que o processo de inovação causou impacto em outras dimensões das atividades das empresas (Figura 7). Foram mudanças mais qualitativas e de natureza organizacional, consequiência indireta mais valiosa das inovações implementadas.

Figura 7

Finalidade das mudanças organizacionais introduzidas

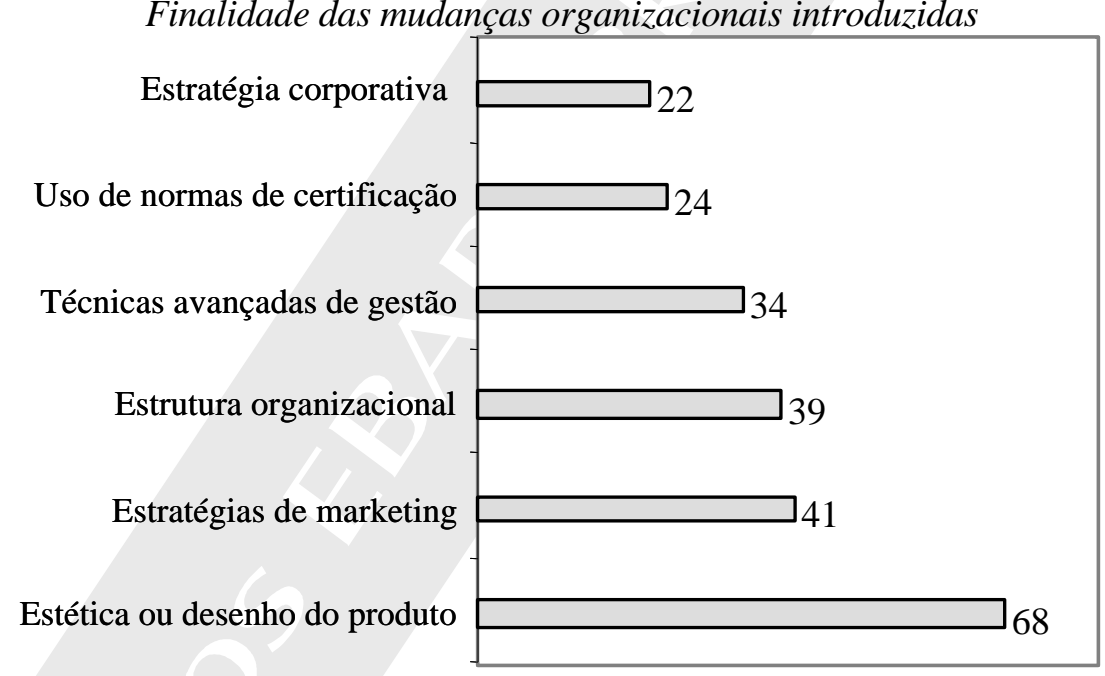

Fonte: IBGE (Pesquisa Industrial Inovação Tecnológica - Pintec 2000, a partir da tabela 29).

\subsection{As dificuldades}

Um número elevado de empresas mencionaram o abandono ou o fracasso de seus projetos. Nesse sentido, é importante identificar os principais fatores que funcionam como obstáculos ou freios a uma gestão mais dinâmica dos recursos tecnológicos. A gestão da tecnologia e da inovação é efetivamente uma atividade arriscada, cujos resultados serão sempre incertos, e as novas tecnologias não são facilmente transformadas em novos produtos ou serviços bem sucedidos no mercado. Das 22.700 empresas que implementaram inovações, cerca de 55\% afirmaram ter encontrado problemas que tornaram mais lenta a implementação de determinados projetos ou que os inviabilizaram. Essa percentagem não varia de maneira significativa em função do tamanho da empresa. 
Os problemas mencionados com mais freqüência são, principalmente, os de natureza financeira ou econômica: custos e riscos ligados à inovação e escassez de financiamento adequado. Essa última dificuldade é recorrente, apesar dos programas governamentais objetivando criar mecanismos de financiamento. É, inclusive, a dificuldade de maior peso para as empresas de pequeno porte. As questões relacionadas à falta de pessoal qualificado e à escassez de informação sobre as tecnologias e os mercados compõem um segundo grupo de dificuldades. A fraca resposta dos consumidores é indicada como fator de maior impacto que a falta de informações. Finalmente, são mencionados os problemas associados às possibilidades de cooperação com outras empresas ou instituições e à escassez de oferta de serviços técnicos externos.

\section{Da tecnologia incorporada ao conhecimento}

Até os anos 1960-70, os estudos sobre inovação focalizavam a dimensão técnica, embora já tivesse sido estabelecida, pela teoria econômica, a relação entre o aumento da produtividade e da competitividade das empresas e o crescimento econômico de maneira geral. Entretanto, eram raros os trabalhos acadêmicos analisando de maneira empírica o processo de capacitação tecnológica, a natureza das atividades inovadoras e as modalidades de difusão das inovações. Dessa perspectiva, a Pintec 2000 fornece elementos valiosos para uma analise mais apurada das práticas visando à inovação na indústria brasileira.

Estudos publicados nos últimos anos mostram que tecnologia, inovação e mercado podem e devem ser gerenciados com visão estratégica pelas empresas (TIDD et al., 1997). Por outro lado, reconhecer a centralidade do conceito de conhecimento representa um avanço significativo na compreensão do processo de inovação, o que vai muito além da compra ou substituição de equipamentos. Para poder inovar e aumentar a capacidade de competir ante a concorrência, melhorando o desempenho e a eficiência das operações produtivas, as empresas precisam reunir um conjunto de novos conhecimentos e habilidades.

Apesar do aumento do comércio internacional que acelera a circulação dos bens e equipamentos, apesar das políticas públicas que procuram promover a cooperação em pesquisa e apesar da multiplicidade dos canais possíveis de disseminação das tecnologias, o acesso ao conhecimento (consolidado ou de ponta) exige que se trilhe um caminho longo e incerto, específico de cada setor e próprio de cada empresa.

O limitado número de empresas capazes de desenvolver projetos de inovação e as características essencialmente incrementais desses projetos é preocupante, quando se pretende tornar a economia brasileira mais competitiva. $\mathrm{O}$ diagnóstico das práticas inovadoras das empresas nacionais coloca de maneira bastante clara alguns dos desafios que permanecem para a capacitação tecnológica, após cinco décadas de industrialização intensiva. A base industrial brasileira ainda continua ligada ao padrão de substituição de importações, em que as inovações de produtos são desenvolvidas fora do sistema produtivo nacional. Por isso, ainda não é possível raciocinar em termos de um sistema nacional de inovação (que aparece fragmentado e incompleto), e com a maioria dos segmentos industriais dependendo de fontes externas de tecnologia.

No padrão atual, a inovação ainda corresponde a um esforço, não desprezível, de modernização da tecnologia industrial básica, mediante a compra de equipamentos e maquinário novo, enquanto a importância do aprendizado, mesmo informal, é pouco reconhecida. Nessas condições, as empresas brasileiras não se mostram muito aptas a competir na base do conhecimento e da capacidade de inovação. A capacitação tecnológica das empresas, etapa indispensável para a inovação, ocorre quando há possibilidade de mobilizar diversas fontes internas e externas de conhecimentos, conhecimentos formalizados e codificados como tácitos e específicos.

Alguns aparecem na forma de idéias novas ou invenções, outros são incorporados em equipamentos, máquinas ou infra-estrutura e outros, ainda, nas habilidades e experiências dos indivíduos. Como a produção do conhecimento é pulverizada e distribuída entre várias organizações e instituições, as empresas terão que desenvolver capacidade interna para identificá-las e de estabelecer relações contínuas com elas. Dessa capacidade de aprender com os outros, nasce a capacidade de inovar. A inserção em redes é um dos caminhos mais importantes para o acesso a informações externas. A qualidade e a intensidade das interações com 
fornecedores ou compradores usuários são igualmente fatores essenciais para o acesso à informação, como também para reunir conhecimentos necessários à inovação.

Finalmente, os investimentos, públicos ou privados, para desenvolver novas tecnologias continuam muito aquém do necessário para que a economia brasileira adquira as características de uma economia baseada no conhecimento. Para que essa estratégia se torne mais sistemática, as empresas precisam de um mercado dinâmico, com demandas avançadas e interação entre empresas e setores, de uma oferta de recursos humanos capacitados e de uma cultura e um ambiente jurídico e regulatório que garantam o beneficio dos riscos assumidos.

\section{Conclusões}

A busca do conhecimento é acompanhada de um processo de aprendizado cujas características são produtos da história econômica e dos valores socioculturais do ambiente em que ocorre. O nível de agregação das respostas apresentadas na Pintec 2000 dificulta uma leitura mais apurada. Para muitas perguntas, seria importante dispor de mais informações. Para entender melhor a capacidade de inovação das empresas brasileiras, seria necessário identificar, mais detalhadamente, as características tecnológicas da base produtiva, as modalidades de acumulação, valorização, proteção dos conhecimentos, as formas de organização das áreas de desenvolvimento, produção, marketing da empresa e a capacidade de adotar princípios de parcerias ou interações com outras organizações.

É preciso considerar que a capacitação tecnológica não só é distribuída de maneira extremamente desigual entre países, regiões, setores ou empresas, como também é fortemente concentrada em alguns poucos países industrializados desde os primórdios do sistema capitalista. Assim, para analisar o processo de capacitação, a abordagem histórica é indispensável para que se possa explicar as diferenças de ritmo e intensidade no avanço do progresso técnico em cada país ou região, além de identificar os atores que dele participam e as modalidades utilizadas.

Nesse contexto, a produção e a circulação do conhecimento tornam-se questões estratégicas, enquanto o aprendizado é identificado como o processo essencial para acumular e usar tal conhecimento. $\mathrm{O}$ acesso ao conhecimento está se tornando o fator mais importante para as economias em desenvolvimento que, por enquanto, têm contribuído de forma limitada para a sua produção. Essa situação será rompida somente quando as empresas locais passarem a investir mais em pesquisa e desenvolvimento e, então, poderem desenvolver inovações que irão incorporar novos conhecimentos. A concretização do impacto econômico da inovação depende de uma combinação entre a continuidade dos investimentos em pesquisa e as oportunidades criadas num dado momento pela convergência de tecnologias disponíveis com as estratégias competitivas das empresas e com as características do ambiente econômico interno e externo.

Alguns poucos países conseguiram ampliar consideravelmente a base de conhecimentos, investindo pesadamente em pesquisa cientifica e formação de recursos humanos. Contudo, a globalização econômica está longe de ter assegurado a livre circulação do conhecimento. Dessa forma, a maioria dos países encontra grandes dificuldades para ter acesso a conhecimentos já difundidos em outras partes do mundo e, também, para criar internamente as competências que permitirão aplicar esses conhecimentos no processo produtivo. 


\section{Referências bibliográficas}

ABERNATHY, W. J.; UTTERBACK, J.M... Patterns of industrial innovation. Technology Review, n.80, June/J uly 1978.

BELL, M. Learning and the accumulation of industrial technological capacity in developing countries. In: FRANSMAN; KING (Org.). Technological capability in the Third World. MacMillan Press, 1984.

; PAVITT, K. National capacities for technological accumulation: evidence and implications for developing countries. University of Sussex, SPRU, 1992. Mimeografado.

Technological accumulation and industrial growth: contrasts between developed and developing countries. Industrial and Corporate Change, v.2, n.2, 1993.

CONFEDERAÇÃO NACIONAL DA INDÚSTRIA. Investimentos na indústria brasileira - 1998-2002. Brasília, 2002.

/CEPAL. Investimentos na indústria brasileira (1995-1999) - características e determinantes. Rio de Janeiro, 1997.

EUROPEAN COMISSION (2004). Eurostat - innovation in Europe. Data 1998-2001.

FREEM AN, C. Networks of innovators: a synthesis of research issues. Research Policy, n.20, p.499-514, 1991.

The economics of technical change - critical survey. Cambridge Journal of Economics, n.18, 1994.

INSTITUTO BRASILEIRO DE GEOGRAFIA E ESTATíSTICA. Estatísticas do Cadastro Central de Empresas 2001. Rio de Janeiro, 2003.

INSTTTUTO BRASILEIRO DE GEOGRAFIA E ESTATÍSTICA. Pesquisa Industrial Inovação Tecnológica - Pintec 2000. Rio de Janeiro, 2002.

KATZ, J Technological innovation, industrial organization and comparative advantages of Latin American metalworking industries. In: FRANSM AN,K (Ed.). Technological capability in the Third World. MacMillan Press, 1984.

Domestic technological innovations and dynamic comparative advantages: a further reflection on a comparative case-study program. In: ROSENBERG; FRISCHTAK, C. (Org.). International technology transfer: concepts, measures and comparisons. Praeger Ed., 1985.

LALL, S. Technological capabilities and industrialization. World Development, v.20, n.2, 1992.

LUNDVALL, B-A. Innovation as an interactive process: from user-producer interaction to the national system of innovation. In: DOSI, G. et al.(Ed.). Technical change and economic theory. London: Pinter Publish, 1988.

(Ed.). National systems of innovation: towards a theory of innovation and interactive learning. London: Pinter, 1992.

ORGANISATION FOR ECONOMIC COOPERATION AND DEVELOPM ENT. OECD. 1992. Oslo Manual. The Measurement of Scientific and Technological Activities, Proposed Guidelines for Collecting and Interpreting Technological Innovation Data.

. The knowledge- based economy. 1996. (General distribution. OECD/GD, n.96, p.102).

European Commission. Eurostat. The measurement of scientific and technological activities proposed guidelines for collecting and interpreting technological innovation data. Oslo Manual, 2000.

PAVITT, K. Sectoral patterns of technical change: towards a taxonomy and a theory. Research Policy, 13, 1984.

TIDD, J.; BESSANT, J.; PAVITT, K. Managing innovation - integrating technological, market and organizational change. London: Wiley and Sons, 1997. 